\section{References}

1. Barnes P J. Inhaled corticosteroids for asthma. N Eng J Med 1995; 332: $868-75$.

2. British Thoracic Society, NAC et al. The British Guidelines on Asthma Management: 1995 review and position statement. Thorax 1997; 52(suppl): S1-21.

3. Kamada A K, Szefler S J, Martin R J et al. Issues in the use of inhaled glucocorticoids. Am J Respir Crit Care Med 1996; 153: 1739-48.

4. Pedersen S, O'Byrne P. A comparison of the efficacy and safety of inhaled corticosteroids in asthma. Eur J Allergy Clin Immunol 1997; 39(suppl 39): 1-34.

5. Wong C S, Cooper S, Britton J R et al. Steroid sparing effect of nedocromil sodium in asthmatic patients on high doses of inhaled steroids. Clin Exp Allergy 1993; 23: 370-6.

6. Tamaoki J, Kondo M, Sakai N et al. Leukotriene antagonist prevents exacerbation of asthma during reduction of high dose inhaled corticosteroid. Am J Resp Crit Care Med 1997; 155: 1235-40.

7. Haahtela T, Jarvinsen M, Kave T et al. Effects of reducing or discontinuing inhaled budesonide in patients with mild asthma. $N$ Eng J Med 1994; 331: 700-5.

8. Barnes P J, Adcock I M. Steroid-resistant asthma. Q J Med 1995; 88: $455-68$

9. Szefler S L, Leung D Y M. Glucocorticoid-resistant asthma: pathogenesis and clinical implications for management. Eur Respir $J$ 1997: 10: 1640-7.

10. Pedersen B, Dahl R, Karlsrom R et al. Eosinophil and neutrophil activity in asthma in a one year trial with inhaled budesonide - the impact of smoking. Am J Respir Crit Care Med 1996; 153: 1519-29. 11. CSM/MCA. Focus on corticosteroids. Current problems in pharmacovigilance 1998; 24: 8 .

12. Lipworth B J, Secki J R. Measures for detecting systemic bioactivity with inhaled and intranasal corticosteroids. Thorax 1997 ; 52: 476-82.

13. Packe G E, Douglas J G, McDonald A F et al. Bone density in asthmatics taking high dose inhaled beclomethasone dipropionate and intermittent systemic corticosteroids. Thorax 1992; 47: 414-7.

14. Boulet L-P, Giguere M-C, Milot J et al. Effects of long-term use of high-dose inhaled steroids on bone density and calcium metabolism. $J$ Allergy Clin Immunol. 1994; 94: 796-803.

15. Wisniewski A F, Lewis S A, Green D J et al. Cross sectional investigation of the effects of inhaled corticosteroids on bone density and bone metabolism in patients with asthma. Thorax 1997; 52: 853-60.

16. Cummings R G, Mitchell P, Leeder S. Use of inhaled corticosteroids and the risk of cataracts. N Eng J Med 1997; 337: 8-14

17. Garbe E, LeLorier J, Boivin J-F et al. Inhaled and nasal glucocorticoids and the risk of ocular hypertension or open-angle glaucoma. JAMA 1997; 277: 722-7.

18. Mak V H F, Melchor R, Spiro S G. Easy bruising as a side-effect of inhaled corticosteroids. Eur Respir J 1992; 5: 1068-74.

19. Greening A P, Ind P W, Northfield M et al. Added salmeterol versus higher-dose corticosteroid in asthma patients with symptoms on existing inhaled corticosteroid. Lancet 1994; 344: 219-24.

20. Woolcock A, Lundback B, Ringdal N et al. Comparison of addition of salmeterol to inhaled steroids with doubling of the dose of inhaled steroids. Am J Respir Crit Care Med 1996; 153: 1481-8. 21. Pauwels R A, Lofdahl C G, Postma D et al. Effect of inhaled formoterol and budesonide on exacerbations of asthma. $N$ Eng J Med 1997; 337: 1405-11.

22. Evans D J, Taylor D A, Zetterstrom O et al. A comparison of lowdose inhaled budesonide plus theophylline and high-dose inhaled budesonide for moderate asthma. N Eng J Med 1997; 337: 1412-8. 23. Ukena D, Harnest U, Salcalauskas R et al. Comparison of addition of theophylline to inhaled steroid with doubling of the dose of inhaled steroid in asthma. Eur Respir J 1997; 337: 1412-8.

24. Paggiaro P L, Gianni D, Di Franco A et al. (on behalf of a European Study Group). Comparison of inhaled salmeterol and individually dose-titrated slow-release theophylline in patients with reversible airway obstruction. Eur Respir J 1996; 9: 1689-95.

25. Horwitz R J, McGill K A, Busse W W. The role of leukotriene modifiers in the treatment of asthma. Am J Respir Crit Care Med 1998; 157: 1363-71.

26. Reiss T F, Chervinsky P, Brandon M et al. Montelukast, a once daily leukotriene receptor antagonist, in the treatment of asthma. A multicenter, randomised, double blind trial. Arch Intern Med 1998; 158: $1213-20$.

27. Suissa S, Dennis R, Ernst P et al. Effectiveness of the leukotriene receptor antagonist zafirlukast for mild to moderate asthma. Ann Inter Med 1997; 126: 177-83.

28. Campell L M, Simpson R J, Turbitt M L et al. A comparison of the cost effectiveness of budesonide $400 \mu \mathrm{g} / \mathrm{day}$ and $800 \mu \mathrm{g} / \mathrm{day}$ in the management of mild-to-moderate asthma in general practice. $\mathrm{Br} \mathrm{J}$ Med Economics 1993; 6: 67-74

29. Price D, Appleby J L. Fluticasone propionate: an audit of outcomes and cost-effectiveness in primary care. Respir Med 1998; 92: $351-3$.

30. MIMS. London, Haymarket Medical Ltd, 1998; 261-279.

31. Green M. Transition to CFC-free inhalers. Asthma in Gen

Pract 1998; 6(1): 3-5.

\title{
Recommendations based on guidelines on the management of mild to moderately severe chronic obstructive pulmonary disease: some practical applications in primary care
}

\author{
C P van Schayck, C L A van Herwaarden, P J Barnes, K Jones, J A Knottnerus, D S Postma, C van Weel, E F M Wouters and P Vermeire
}

A variety of clinical guidelines on the management of asthma have appeared over the last ten years. ${ }^{1-6}$ Guidelines for the management of chronic obstructive pulmonary disease (COPD) have also been published, ${ }^{6-13}$ but these are mainly drawn up by thoracic societies and some parts are less relevant for patients with milder forms of COPD or those treated in primary care. The aim of this paper is to provide recommendations (evidence-based where possible) to guide primary care professionals in their management of adult patients with COPD.

A Medline search has been performed over the past 10 years with the combined MESH headings 'COPD' and 'guidelines'. In total 32 published papers were found. Only guidelines for the managment of COPD which were published in English were selected. Only 10 publications met these criteria ${ }^{6-16}$ and none of them were specifically aimed at patients treated in primary care. Based on these publications and on the consensus of the authors, the following guidelines for the management of mild to moderate COPD in primary care are suggested.

In drawing up a plan for the management of patients with COPD, there are a number of important considerations. Firstly, the treatment of the patients should be based on the underlying pathophysiology mechanisms. In this respect there are significant differences between COPD and asthma that have obvious consequences for treatment. ${ }^{6}$ COPD is a generic term for chronic bronchitis, emphysema and a disorder of the peripheral airways, of which chronic progressive irreversible airflow obstruction is the 
Onno van Schayck ${ }^{1}$

Professor, Epidemiologist

Chris van Weel ${ }^{1}$

Professor, GP

Department of General

Practice and Social

Medicine

\section{Cees van Herwaarden ${ }^{1}$}

Professor, Chest Physician

Department of Pulmonary

Diseases

${ }^{1}$ University of Nijmegen, PO Box 9101, $6500 \mathrm{HB}$,

Nijmegen,

The Netherlands.

\section{Peter Barnes}

Professor, Chest Physician

National Heart and Lung Institute, Royal Brompton Hospital, London, UK.

\section{Kevin Jones}

Senior Lecturer in Primary Health Care

Department of Primary Health Care, University of Newcastle, Newcastle, UK

\section{Andre Knottnerus}

Professor, GP

Department of General Practice

Emiel Wouters ${ }^{2}$

Professor, Chest Physician

Department of Pulmonary Diseases

${ }^{2}$ University of Maastricht, Maastricht,

The Netherlands.

\section{Dirkje Postma}

Professor, Chest Physician

Department of Pulmonary Diseases, Groningen

University, Groningen,

The Netherlands.

\section{Paul Vermiere}

Professor, Chest Physician

Department of Pulmonary Diseases, University of

Antwerp, Antwerp,

Belgium.

Correspondence to:

Prof. C P van Schayck

Date received: 09/07/98

Date accepted: 16/11/98

Asthma in Gen Pract 1998; 6(3): 35-39.
Table 1: Diseases that may lead to chronic irreversible airflow obstruction

Chronic bronchitis
Chronic bronchiolitis (small airways disease)
Emphysema
Chronic asthma
Bronchiectasis
Primary ciliary dyskinesia
Cystic fibrosis
Pulmonary tuberculosis
Sarcoidosis
Obliterative bronchiolitis

common hallmark. Asthma, on the other hand, is characterised by episodes of reversible airflow obstruction. As there are mixed forms it is sometimes difficult to make a distinction between adult asthma and COPD, especially in the early onset of the diseases which often present in primary care. In addition, chronic airflow obstruction occurs in several other diseases (Table 1), which also hampers a clear diagnosis of COPD. By the nature of their discipline, general practitioners focus mainly on the presentation of symptoms, which often do not give a clear distinction between asthma and COPD. Therefore, we have recently proposed pragmatic (partly symptombased) primary care definitions of asthma and COPD. ${ }^{17}$ COPD was defined as chronic cough and/or chronically increased sputum production and/or effort dyspnoea combined with chronic airflow obstruction with little or no reversibility. ${ }^{17}$

A treatment plan for patients with chronic airflow obstruction has to be adapted for each patient. The ideas for management formulated here are based on COPD in its narrowest sense, namely where the chronic airflow obstruction is caused by an airway component and/or emphysema mostly due to smoking. Even the group that is defined in this way is heterogeneous. Although cigarette smoking is strongly associated with its development, COPD may also incidentally occur in those who never smoke. Moreover, COPD may manifest itself in different clinical patterns. In one patient chronic cough and excessive mucus production may be prominent (chronic bronchitis), whereas in another symptoms of dyspnoea associated with the destruction of lung parenchyma (emphysema) are present. The factors determining these differences are not yet fully understood. Respiratory and skeletal muscle weakness (probably related to loss of muscle mass) might be considered as well as lung function impairment in the presence of impaired exercise tolerance. ${ }^{18}$

In this paper we present an agreed treatment plan for patients with stable, mild and moderately severe COPD (Table 2). Patients with a forced expiratory volume in one second $\left(\mathrm{FEV}_{1}\right)$ of more than approximately $50 \%$ of the predicted value ${ }^{19}$ and with normal arterial blood gases at rest and on submaximal exercise are considered as patients with moderately severe COPD. In severe COPD other aspects are involved, which will

Table 2: Classification of the severity of COPD, based on FEV

$\begin{array}{ll}\text { Mild } & \text { FEV }_{1} 60-80 \% \text { predicted } \\ \text { Moderate } & \text { FEV }_{1} 40-59 \% \text { predicted } \\ \text { Severe } & \text { FEV }_{1}<40 \% \text { predicted }\end{array}$

not be covered in these recommendations. We suggest that patients with severe COPD or recurrent severe exacerbations should be under the management of a specialist. Given the chronic and gradually progressive nature of COPD, not only does pharmacological treatment of the condition at organ level play an important part, but treatment should also be directed at preventing and/or delaying the development of functional limitation and handicap. An extensive discussion of this non-pharmacological treatment is beyond the scope of this paper.

\section{AIMS OF TREATMENT}

Treatment of COPD is generally aimed at:

- reducing symptoms and improving quality of life;

- optimising lung function;

- avoiding unnecessary use of medication;

- preventing and treating exacerbations;

- reducing the annual decline in lung function;

- secondary (and tertiary) prevention of impaired functional health.

The most important symptoms of COPD are breathlessness and coughing. Breathlessness impedes the patient in everyday life; therefore, improving lung function, in the short as well as the long-term, is of great importance. However, there is not a good correlation between the presence of dyspnoea and the severity of airflow obstruction. For diagnosis and therapy, repeated lung function measurements are indispensable. In COPD, peak expiratory flow (PEF) provides insufficient information about the diameter of the smaller airways, a much better index of the severity and progression of COPD is the $\mathrm{FEV}_{1}$ value. $^{17}$

Treatment should be aimed at reaching a $\mathrm{FEV}_{1}$ value that is as high as possible and therefore requires repeated assessment.

\section{TREATMENT STRATEGY}

Lifestyle changes are at the core of successful treatment in COPD. In particular, stopping smoking and avoidance of other inhaled irritants are very important Nicotine chewing gum, skin patches or spray might be helpful. It is important to pay repeated attention to smoking cessation as prevention of infections and pharmacotherapy are probably much more efficacious following cessation. Pharmacological treatment of COPD includes:

1. dilation of the airways by using bronchodilators;

2. supressing the inflammatory component in the airways by using anti-inflammatory therapy;

3. increasing protection with antioxidants, because the balance may be disturbed due to an increased amount of free radicals in the airways.

The clinical efficacy of anti-inflammatory and antioxidant treatment is still under study. Therefore, a treatment plan for COPD is less evidence-based than for asthma. A step-wise treatment plan of mild and moderately severe COPD is summarised in Table 3.

\section{Step 1: Preventive measures}

To prevent further damage to the airways and alveoli, preventive measures should be advised first. It is of utmost importance for patients to stop smoking. Once smoking has stopped, symptoms of bronchitis in the form of coughing and sputum production will usually decrease after some time. The effect of smoking on the progressive decline in lung function is of greater 
importance. Following smoking cessation, the annual rapid decline of the $\mathrm{FEV}_{1}$ is usually reduced, sometimes to the level of non-smokers. ${ }^{20}$ The presence of air pollution caused by substances other than smoke in the patient's immediate environment may also contribute to a deterioration of symptoms and an increased decline in the FEV ${ }_{1 .}^{21}$ Avoidance of such stimuli - including in the workplace - is therefore of great importance.

Recurrent exacerbations caused by viral and/or bacterial respiratory infections are a frequent problem in patients with COPD. An annual influenza vaccination is associated with a substantial reduction of severe morbidity and mortality. ${ }^{22}$

\section{Step 2: Treatment with bronchodilators}

Bronchodilators diminish bronchial obstruction by relaxation of airway smooth muscle. Even without a clear increase in $\mathrm{FEV}_{1}$ dyspnoea may decrease, possibly because of a reduction of dynamic hyperinflation during exercise.

Bronchodilator medication may be divided in three types: anticholinergic drugs, $\beta_{2}$-agonists and theophylline. Start preferably with inhaled anticholinergics or $\beta_{2}$-agonists. Patients with mild COPD may use bronchodilators regularly, since this does not adversely influence the course of lung function, ${ }^{20,23}$ as was previously observed in rapid progressive asthma and COPD. ${ }^{24}$

\section{Anticholinergic drugs}

If used, the anticholinergic drug, ipratropium bromide, has to be taken three to four times daily; oxitropium bromide may be used twice daily. A disadvantage of anticholinergic drugs is that the bronchodilator effect begins about 30 minutes after administration. To promote reliable inhalation of these drugs, it should be pointed out to the patient that these drugs differ from $\beta_{2}$-agonists (which reach their maximum effect after five to 15 minutes). In some studies, maximally attainable bronchodilation is greater after anticholinergics than after $\beta_{2}$-agonists; ${ }^{25-27}$ in others, however, a similar response to the two types of bronchodilators is seen. ${ }^{28,29}$ Where the first prescribed bronchodilator has insufficient effect, it can be changed, e.g. from ipratropium bromide to a $\beta_{2}$-agonist or vice versa. Compared to placebo, an additional favourable effect of ipratropium bromide relates to a decrease in the frequency and severity of coughing, combined with a reduction of the amount of sputum, yet without negative effects on mucociliary clearance..$^{30}$

\section{$\beta_{2}$-agonists}

Inhaled $\beta_{2}$-agonists are also effective in COPD. Shortacting $\beta_{2}$-agonists, such as salbutamol, terbutaline sulphate and fenoterol hydrobromide, have to be used three to four times daily. Although little is known about the effect of the inhaled long-acting $\beta_{2}$-agonists, eformoterol fumarate and salmeterol in COPD, these drugs may be useful, particularly for the treatment of morning dyspnoea. Several studies have shown beneficial effects of salmeterol on symptoms and peak expiratory flow measurements in patients with COPD. ${ }^{31,32}$ Quality of life especially seems to improve during use of long-acting $\beta_{2}$-agonists. ${ }^{32}$

If the effect of one of these medicines alone is insufficient, they can be used in combination. It may be appropriate to consider a long-acting $\beta_{2}$-agonist twice daily in combination with ipratropium bromide (or oxitropium bromide) twice daily, or a short-acting $\beta_{2}$-agonist with ipratropium bromide both three to four times daily, possibly in a combined preparation. ${ }^{33}$

Theophylline

Theophylline has a clear bronchodilator effect, although it is weaker than inhaled bronchodilators. Theophylline is effective in serum concentrations between 5 and $16 \mu \mathrm{g} / \mathrm{ml}$. When theophylline is used, regular determinations of the serum concentration are necessary. Stable serum concentrations can only be achieved using sustained-release preparations; administered once or twice daily. Theophylline is considered as a third-line bronchodilator in moderately severe COPD, it is used more often in patients with severe COPD ( $\mathrm{FEV}_{1}<40 \%$ predicted) and in this case very often in addition to a $\beta_{2}$-agonists and/or ipratropium bromide. The efficacy in such patients is possibly due to other, non-bronchodilator effects of theophylline, such as a central stimulant effect on respiration and possibly an improvement in respiratory muscle function. ${ }^{34}$

Assessing the effect of a bronchodilator After a patient has started using bronchodilators, it is important to assess the effect on dyspnoea, $\mathrm{FEV}_{1}$ and exercise tolerance, at least every six months.

\section{Step 3a: Consider an inhaled steroid trial} Many patients with COPD are treated with inhaled corticosteroids; this is controversial because of differences in the pathogenesis and pathophysiology of asthma and COPD..$^{35,36}$ A number of studies in patients with COPD have indeed shown no effect, or only a limited effect, of inhaled corticosteroids on symptoms and course of lung function. ${ }^{37-40}$ However, these studies were either short-term,,$^{37-39}$ uncontrolled, ${ }^{40}$ or used protocols without distinction between asthma or COPD. ${ }^{41}$ The effect of long-term treatment is currently being investigated in several studies. The following considerations may be important in prescribing a trial of treatment:

1. in COPD patients with features of asthma (such as symptoms of hyper-responsiveness), administering inhaled corticosteroids seems to be useful, given the underlying pathophysiologic process; ${ }^{42}$

2. if there is a rapid decline in lung function, a trial treatment with corticosteroids may be considered. ${ }^{40}$

When a trial of inhaled steroids is started (beclomethasone dipropionate, budesonide or fluticasone propionate), it is important they are prescribed in a sufficiently high dose, e.g. $800 \mu \mathrm{g}$ daily. Evaluation of the effect is advised after six months on the basis of symptoms, exacerbation rate and lung function. In the meantime, inhalation technique and compliance with therapy should be assessed.

Depending on the effect, inhaled steroids can either be continued or stopped. The safety of inhaled steroids is considered acceptable at these doses; a routine check of adrenal function or bone metabolism is not currently advised in adults.

Another possibility is to start with a burst of oral prednisolone in a dosage of 30-40 mg daily over at least two to four weeks. A meta-analysis demonstrated that approximately $10 \%$ of patients with stable COPD treated 
with oral steroids had an increase in the $\mathrm{FEV}_{1}$ of approximately $20 \%$ of baseline. ${ }^{43}$ If $\mathrm{FEV}_{1}$ improves, continuation with inhaled steroids may be considered, however, this does not automatically imply that inhaled steroids will be beneficial. It is important to evaluate the contribution of their use at each checkup.

\section{Step 3b: Consider a trial of treatment with} $\mathrm{N}$-acetylcysteine (NAC) in recurrent exacerbations In some studies it has been demonstrated that treatment with $600 \mathrm{mg} /$ day of NAC in patients with COPD may lead to an improvement of symptoms such as the frequency of coughing and the amount and viscosity of the sputum. ${ }^{44,45}$ The exacerbation rate and the number of sick days has been shown to decrease during daily use over a period of six months. ${ }^{447}$ The effects of NAC do not seem to be explained by the mucolytic property of the preparation, because such effects were not found during treatment with iodinated glycerol, a mucolytic without antioxidant action. ${ }^{48}$ These effects are probably explained by the antioxidant action of NAC. In the gastrointestinal tract cysteine is separated from NAC. Cysteine is a precursor of glutathione, a non-enzymatic antioxidant which plays an essential role in the metabolic protection against reactive oxygen species ('free radicals'). In vitro, NAC reduces the increased production of reactive oxygen species by alveolar

Table 3: Maintenance treatment of mild and moderately severe COPD

Step 1: Preventative measures

- stop smoking,

- if possible, remove sensitisers from the environment,

- annual vaccination against influenza.

Step 2: Treat with bronchodilators

- anticholinergics or $ß_{2}$-agonists,

- if effect is insufficient use other bronchodilator(s) or in combination

- if insufficient response consider theophylline,

- if insufficient improvement consider STEP 3A and/or 3B.

Step 3A: Trial treatment with inhaled corticosteroids - assess effect and evaluate after six months.

Step 3B: Trial treatment with $\mathrm{N}$-acetylcysteine in case of recurrent exacerbations

- assess effect and evaluate after six months.

Table 4: Indications for specialist referral (based on BTS Guidelines) ${ }^{13}$

\begin{tabular}{|c|c|}
\hline Reason & Purpose \\
\hline Suspected severe COPD. & $\begin{array}{l}\text { To confirm diagnosis } \\
\& \text { optimise treatment. }\end{array}$ \\
\hline Onset of cor pulmonale. & $\begin{array}{l}\text { To confirm diagnosis } \\
\& \text { optimise treatment. }\end{array}$ \\
\hline Assessment for $\mathrm{O}_{2}$ therapy. & To measure blood gases. \\
\hline $\begin{array}{l}\text { Assessment in accordance } \\
\text { with nebuliser guidelines. }\end{array}$ & $\begin{array}{l}\text { To exclude inappropriate } \\
\text { prescriptions. }\end{array}$ \\
\hline Bullous lung disease. & $\begin{array}{l}\text { To identify \& assess } \\
\text { candidates for surgery. }\end{array}$ \\
\hline $\begin{array}{l}\text { COPD in patient less than } \\
40 \text { years. }\end{array}$ & $\begin{array}{l}\text { To identify } \alpha_{1-a n t i t r y p s i n} \\
\text { deficiency, consider } \\
\text { therapy \& screen family. }\end{array}$ \\
\hline $\begin{array}{l}\text { Symptoms disproportionate } \\
\text { to lung function deficit. }\end{array}$ & $\begin{array}{l}\text { To look for other } \\
\text { explanations. }\end{array}$ \\
\hline Frequent infections. & $\begin{array}{l}\text { To exclude } \\
\text { bronchiectasis. }\end{array}$ \\
\hline
\end{tabular}
macrophages in response to cigarette smoke. ${ }^{49}$ Beneficial effects were also found with regard to the function of neutrophilic granulocytes, fibroblasts and epithelial cells. ${ }^{50}$

There are indications that in patients with COPD, maintenance treatment with NAC reduces the number of bacterial colonies in the lower airways, which results in a decrease in the exacerbation rate. ${ }^{51}$ In addition, NAC prevents oxidative inactivation of $\alpha_{1}$-proteinase inhibitor $\left(\alpha_{1-}\right.$ PI), the most important protector of the lower airways against neutrophil elastase. ${ }^{52}$ This is important, as this inactivation of $\alpha_{1}-\mathrm{PI}$ is thought to play an essential role in the development and progression of emphysema. ${ }^{53}$ Recently the results of an open study showed that NAC in a dosage of $600 \mathrm{mg} /$ day over a period of two years slowed the decrease in $\mathrm{FEV}_{1}$ in patients with COPD, compared to a reference group of similar patients without NAC. ${ }^{54}$ Both groups were treated with inhaled bronchodilators. However, the favourable effect was only significantly different in patients aged over 50. Based on the above-mentioned findings, a trial treatment with NAC may be considered in patients with recurrent exacerbations, although controlled studies with respect to the long-term effects of NAC are urgently needed. We recommend NAC (not licensed in $U K-$ Editor) in a dosage of at least $600 \mathrm{mg} /$ day over six months in order to assess the effect; the effect of treatment will determine whether or not to continue this medication.

\section{Checking compliance with therapy and inhalation} technique before changing medication

The efficacy of all medication should be assessed repeatedly. It should be ascertained that there is optimal compliance with therapy and inhalation technique before any type of medication is changed or added.

\section{Treatment of exacerbations}

Exacerbations are mostly caused by viral and/or bacterial respiratory infections. They are accompanied by an increase in dyspnoea, a change in cough pattern and in the nature and production of the sputum. Exacerbations should be treated by intensifying the bronchodilator therapy, supplemented with a burst of oral corticosteroids if necessary. Corticosteroids are indicated for a decrease in $\mathrm{FEV}_{1}$ by $40 \%$ or more compared to personal best, or where there is marginal lung function. With severe disorders of lung function, blood gas monitoring may be indicated. Antibiotics are only indicated in the case of bacterial respiratory infections, if treatment with bronchodilators and corticosteroids has insufficient effect (or had insufficient effect in the past).

\section{Referral to hospital specialist}

There are several reasons for a referral to a hospital specialist at different stages of the disease. In Table 4 we have summarized the most important reasons (and their purpose) based on the BTS guidelines. ${ }^{13}$

\section{SUMMARY}

Treatment of patients with mild and moderately severe COPD is schematically represented in Table 3.

- Preventive measures include stopping smoking, avoiding inhalation of sensitisers and annual vaccination against influenza.

- Treatment is primarily directed at reducing dyspnoea and recurrent exacerbations. Optimal lung function should be aimed for, in the short and long-term.

- Bronchodilators should be administered to reduce chronic airflow obstruction.

- In COPD the efficacy of inhaled corticosteroids has to be proven. A favourable effect on airflow obstruction can be expected in patients with an asthmatic component. A trial of treatment should evaluate the effectiveness.

- In the case of recurrent exacerbations chronic use of NAC may have a favourable effect. A trial of treatment might be considered.

- In the case of insufficient treatment effect after six months, other determining factors of respiratory symptoms (impaired diffusion capacity, respiratory or skeletal muscle weakness) have to be considered.

\section{References}

1. Statement by the British Thoracic Society. Guidelines for management in adults: I-chronic persistent asthma. BMJ 1990; 301: 651-3.

2 . Statement by the British Thoracic Society. Guidelines for management in adults: II-Acute severe asthma. BMJ 1990; 301: 797-800.

3. National Heart, Lung and Blood Institute. Expert panel report. 
Guidelines for the diagnosis and management of asthma. J Allergy Clin Immunol 1991; 88: 425-534.

4. National Heart, Lung and Blood Institute. International concensus report on diagnosis and treatment of asthma. Eur Respir J 1992; 5: 601-41.

5. National Institues of Health/WHO. Global initiative for asthma. Bethesda: NIH, 1995.

6. Official statement of The American Thoracic Society. Standards for the diagnosis and care of patients with chronic obstructive pulmonary disease (COPD) and asthma. Am Rev Respir Dis 1987; 136: 225-44. 7. Tiep B L. Long-term home oxygen therapy. Clin Chest Med 1990; 11: 505-21.

8. Canadian Thoracic Society Workshop Group. Guidelines for the assessment and management of chronic obstructive pulmonary disease. Can Med Assoc J 1992; 147: 420-8.

9. Fergusson G T, Cherniack R M. Management of chronic obstructive pulmonary disease. N Engl J Med 1993; 328: 1017-22.

10. Ketelaars C A, Saad H H, Halfens R J et al. Process standards of nursing care for patients with COPD: validation of standards and criteria by the Delphi technique. J Nurs Care Qual 1994; 9: 78-86. 11. American Thoracic Society Statement. Standards for the diagnosis and care of patients with chronic obstructive pulmonary disease. Am J Respir Crit Care Med 1995; 152: S77-120.

12. Siafakas N M, Vermeire P, Pride N B et al. Optimal assessment of chronic obstructive pulmonary disease. Eur Respir J 1995; 8: 1398-420.

13. British Thoracic Society guidelines for the management of chronic obstructive pulmonary disease. Thorax 1997; 52: S1-28.

14. Maltais F, Bourbeau J. Medial management of emphysema. Chest Surg Clin NAm 1995; 5: 673-89.

15. Chapman K R. Therapeutic approaches to chronic obstructive pulmonary disease: an emerging consensus. Am J Med 1996; 100: $5 s-10$ s.

16. Wilkinson J, Rees J. Domiciliary oxygen. Br J Clin Pract 1996; 50: $151-3$.

17. van Schayck C P, Barnes P J, Jones K et al. Diagnosis of asthma and chronic obstructive pulmonary disease in general practice. $\mathrm{Br} \mathrm{J}$ Gen Pract 1996; 46: 193-7.

18. Schols A M W J, Mostert R, Soeters P B et al. Body composition and exercise performance in patients with chronic obstructive pulmonary disease. Thorax 1991; 46: 695-9.

19. Quanjer P H, Tammeling G J, Cotes J E et al. Lung volumes and forced ventilatory flows. Official statement of the European Respiratory Society. Eur Respir J 1993; 6 (Suppl 16): 5-40. 20. Anthonissen N R, Connett J E, Kiley J P et al. Effects of smoking intervention and the use of an inhaled anticholinergic bronchodilator on the rate of decline of FEV 1 . The Lung Health Study. JAMA 1994; 272: $1497-505$.

21. Tashkin D P, Detels R, Simmons M et al. The UCLA population studies of chronic obstructive respiratory disease: XI. Impact of air pollution and smoking on annual change in forced expiratory volume in one second. Am J Respir Crit Care Med 1994; 149: 1209-17. 22. Nichol K L, Margolis K L, Wuorenma J et al. The efficacy and cost effectiveness of vaccination against influenza among elderly persons living in the community. N Engl J Med 1994; 331: 778-84. 23. van Schayck C P, Dompeling E, van Herwaarden C L A et al. Continuous and on demand use of bronchodilators in patients with non-steroid dependent asthma or chronic bronchitis: four year followup randomized controlled study. Br J Gen Pract 1995; 45: 239-44. 24. van Schayck C P, Dompeling E, van Herwaarden C L A et al. Bronchodilator treatment in moderate asthma or chronic bronchitis: continuous or on demand? A two-year randomized controlled study with salbutamol and ipratropium bromide. Br Med J 1991; 303: 1426-31.

25. Marini J J, Lakshminarayan S, Kradjan W A. Atropine and terbutaline aerosols in chronic bronchitis: efficacy and sites of action. Chest 1981; 80: 285-91.

26. Braun S R, Levy S F. Comparison of ipratropium bromide and albuterol in chronic obstructive pulmonary disease: a threecenter study. Am J Med 1991; 91: 28S-32S.

27. van Schayck C P, Folgering H T M, Harbers H et al. Effects of allergy and age on responses to salbutamol and ipratropium bromide in moderate asthma and chronic bronchitis. Thorax 1991; 46: 355-9. 28. Easton P A, Jadue C, Dhingra S et al. A comparison of the bronchodilating effects of a $\beta_{2}$-adrenergic agent (albuterol) and an anticholinergic agent (ipratropium bromide), given by aerosol alone or in sequence. N Engl J Med 1986; 315: 735-9.

29. Karpel J P, Pesin J, Greenberg D et al. A comparison of the effects of ipratropium bromide and metaproterenol sulfate in acute exacerbations of COPD. Chest 1990; 98: 835-9.
30. Ghafouri M A, Patil K D, Kass I. Sputum changes associated with the use of ipratropium bromide. Chest 1984; 86: 387-93.

31. Ulrik C S. Efficacy of inhaled salmeterol in the management of smokers with chronic obstructive pulmonary disease: a single centre randomised, double blind, placebo controlled, crossover study. Thorax 1995; 50: 750-4.

32. Jones P W, Bosh T K. Quality of life changes in COPD patients treated with salmeterol. Am J Respir Crit Care Med 1997; 155: 1283-9.

35. Postma D S. Inhaled therapy in COPD: what are the benefits? Respir Med 1991; 85: 447-9.

36. van Schayck C P, van Grunsven P M, Dekhuijzen P N R. Do patients with COPD benefit from treatment with inhaled corticosteroids? Eur Respir J 1996; 9: 1969-72.

37. Auffarth B, Postma D S, de Monchy J G R et al. Effects of inhaled budesonide on spirometric values, reversibility, airway responsiveness, and cough threshold in smokers with chronic obstructive lung disease. Thorax 1991; 46: 372-7.

38. Watson A, Lim T K, Joyce $\mathrm{H}$ et al. Failure of inhaled corticosteroids to modify bronchoconstrictor or bronchodilator responsiveness in middle-aged smokers with mild airflow obstruction. Chest 1992; 101: 350-5.

39. Paggario P L, Dahle R, Bakran I et al. Multicentre randomised placebo-controlled trial of inhaled fluticasone propionate in patients with chronic obstructive pulmonary disease. International COPD Study Group. Lancet 1998; 351: 773-80.

40. Dompeling E, van Schayck C P, van Grunsven P M et al. Slowing the deterioration of asthma and chronic obstructive pulmonary disease observed during bronchodilator therapy by adding inhaled corticosteroids. A four year prospective study. Ann Intern Med 1993 118: $770-8$.

41. Kerstjens H A M, Brand P L P, Hughes M D et al. A comparison of bronchodilator therapy with or without inhaled corticosteroid therapy for obstructive airways disease. $N$ Engl J Med 1992; 327: 1413-9.

42. Kerstjens H A M, Overbeek S E, Schouten J P et al. Airway hyperresponsiveness, bronchodilator response, serum IgE, and smoking habit predict improvement in $\mathrm{FEV}_{1}$ during long-term inhaled corticosteroid treatment. Eur Respir J 1993; 6: 868-76. 43. Callahan C M, Dittus R S, Katz B P. Oral corticosteroid therapy for patients with stable chronic obstructive pulmonary disease. A meta-analysis. Ann Intern Med 1991; 114: 216-23. 44. Multicenter study group. Longterm oral acetylcysteine in chronic bronchitis. A doubleblind controlled study. Eur J Respir Dis 1980; 61 (Suppl 111): 93-108.

45. Aylward M, Maddock J, Dewland P. Clinical evaluation of acetylcysteine in the treatment of patients with chronic obstructive bronchitis: a balanced doubleblind trial with placebo control. Eur J Respir Dis 1980; 61 (Suppl 111): 81-9.

46. Boman G, Backer U, Larsson S et al. Oral acetylcysteine reduces exacerbation rate in chronic bronchitis: report of a trial organized by the Swedish Society for Pulmonary Diseases. Eur J Respir Dis 1983; 64: 405-15.

47. Rasmussen J Band Glennon C. Reduction in days of illness after longterm treatment with $\mathrm{N}$-acetylcysteine controlled release tablets in patients with chronic bronchitis. Eur Respir J 1988; 1: 351-5.

48. Petty T L. The national mucolytic study. Results of a randomized, doubleblind, placebo-controlled study of ionidated glycerol in chronic obstructive bronchitis. Chest 1990; 97: 75-83. 49. Bergstrand H, Björnson A, Eklund A et al. Stimuli-induced superoxide radical generation in vitro by human alveolar macrophages from smokers: modulation by $\mathrm{N}$-acetylcysteine treatment in vivo. J Free Rad Biol Med 1986; 2: 119-27. 50. van Herwaarden C L A, Bast A, Dekhuijzen P N R. The role of $\mathrm{N}$-acetylcysteine in the treatment of chronic obstructive pulmonary disease. Neth J Med 1995; 47: 45-8.

51. Riise G C, Larsson S, Larsson P et al. The intrabronchial microbial flora in chronic bronchitis patients: a target for Nacetylcysteine therapy? Eur Respir J 1994; 7: 94-101.

52. Borregaard N, Jensen H S, Bjerrum O W. Prevention of tissue damage: inhibition of myeloperoxidase mediated inactivation of alpha 1-proteinase inhibitor by $\mathrm{N}$-acetylcysteine, glutathione and methionine. Agents Actions 1987; 22: 255-60.

53. Janoff A. Elastases and emphysema. Current assessment of the protease-antiprotease hypothesis. Am Rev Respir Dis 1985; 132: 417-33.

54. Lundbäck B, Lindström M, Andersson S et al. Possible effect of acetylcysteine on lung function. Eur Respir J 1992; 5 (Suppl 15): 289s. 